\title{
EFEITO DO REFINO DO TAMANHO DE GRÃO AUSTENÍTICO PELA ADIÇÃO DE HÁFNIO (Hf) NAS PROPRIEDADES MECÂNICAS DE TRAÇÃO DO AÇO HADFIELD*
}

\author{
Bianka Nani Venturelli \\ Eduardo Albertin ${ }^{2}$ \\ Cesar Roberto de Farias Azevedo ${ }^{3}$
}

\section{Resumo}

Estudou-se o efeito do tamanho de grão austenítico nas propriedades de tração do aço Hadfield refinado com Hf. Estas propriedades foram comparadas com as de um aço Hadfield sem refino, ambos com a composição química de acordo com a norma ASTM A128 - grau B2. Adicionalmente, foram usadas técnicas de caracterização macroestrutural, microestrutural e fractográfica. A caracterização macroestrutural mostrou que o aço Hadfield com adição de $\mathrm{Hf}$ apresentou tamanho do grão austenítico $(600 \mu \mathrm{m})$ aproximadamente cinco vezes menor do que o do aço Hadfield sem refino $(3000 \mu \mathrm{m})$. Os resultados do ensaio de tração mostraram um pequeno aumento $(\sim 6 \%)$ no valor do limite de escoamento com o refino do grão, em acordo com a Equação de Hall-Petch para materiais austeníticos. No entanto, os resultados dos ensaios de tração do aço Hadfield refinado mostraram aumentos que não foram previstos para as propriedades de resistência à tração ( 37\%), alongamento ( 53\%) e tenacidade ( 88\%). O exame fractográfico dos corpos de prova de tração indicou predominância do mecanismo de fratura dúctil para o aço Hadfield sem refino, enquanto que o aço Hadfield refinado apresentou predominância do mecanismo de fratura intergranular dúctil.

Palavras-chave: Aço Hadfield; Refino do grão austenítico; Adição de háfnio; Propriedades mecânicas de tração.

\section{EFFECT OF THE AUSTENITE GRAIN REFINEMENT OBTAINED BY THE ADDITION OF HAFNIUM (Hf) ON THE TENSILE PROPERTIES OF HADFIELD STEEL}

\section{Abstract}

This paper studies the effects of austenite grain size in the tensile properties of Hadfield steel refined with addition of $\mathrm{Hf}$. These properties were compared with nonrefined Hadfield steel, both with chemical composition as described in ASTM A128 grade B2. Additionally, techniques of macro-structural, micro-structural and fractographic characterization were used. Macro-structural characterization shows that Hadfield steel with addiction of $\mathrm{Hf}$ has grain size five times smaller than nonrefined Hadfield steel $(3000 \mu \mathrm{m}$ to $600 \mu \mathrm{m})$. Tensile test results showed that yield strength value had a little increment $(\sim 6 \%)$, in accordance with Hall-Petch Equation. In contrast, the tensile test results showed an unexpected increase on the properties of tensile strength $(\sim 37 \%)$, area reduction ( $53 \%)$ and toughness ( $88 \%)$. The fractographic exam of the tensile specimens shows that non-refined Hadfield steel has predominance of the mechanism of ductile fracture and the refined Hadfield steel has predominance of the mechanism of intergranular ductile fracture.

Keywords: Hadfield steel; Refinement of grain size; Hafnium addition; Mechanical properties.

Mestranda em Engenharia de Metalúrgica e de Materiais - Departamento de Engenharia Metalúrgica e de Materiais da Escola Politécnica, Universidade São Paulo.

Pesquisador Pleno do Instituto de Pesquisa Tecnológica do Estado de São Paulo (IPT)

3 Professor Doutor do Departamento de Engenharia Metalúrgica e de Materiais da Escola Politécnica, Universidade São Paulo. 


\section{INTRODUÇÃO}

Em 1882, Sir Robert Abbot Hadfield estudou em Sheffield (Inglaterra) o efeito das adições de $\mathrm{Mn}$ e $\mathrm{C}$ em aço carbono [1,2]. Ele utilizou uma razão de 1/10 entre os teores de $\mathrm{C}$ e $\mathrm{Mn}$ e os resultados indicaram que os aços com teores de $1-1.4 \% \mathrm{C}$ e $10-14 \% \mathrm{Mn}$ apresentaram aumento nas propriedades mecânicas de tração, de resistência ao desgaste e de tenacidade à fratura quando comparados aos aços carbono $[1,2]$.

O Mn em aços Hadfield atua como estabilizador da fase austenita, reduzindo a temperatura de início da transformação martensítica (Ms) e retardando a reação de decomposição da austenita durante o resfriamento do aço tanto após o processo de fundição quanto após o tratamento térmico de homogeneização [3]. Os aços Hadfield possuem elevada capacidade de encruamento em serviço pela deformação plástica da austenita, fato que aumenta a dureza superficial destes aços de $190 \mathrm{HB}$ na condição não deformada para valores em torno de 500 HB quando deformados $[4,5,6]$. No entanto, a principal propriedade destes aços é a sua tenacidade, que possibilita o seu uso em aplicações que envolvem desgaste associado com impacto, como em alguns componentes da indústria de mineração (mandíbulas e giratórios na britagem primária de minérios), e na indústria ferroviária (desvios e cruzamentos ferroviários) [6]. Tendo em vista a grande participação da indústria de mineração na economia do Brasil [7], é relevante o desenvolvimento de inovações aplicáveis a esses componentes.

As composições químicas dos vários graus comerciais do aço Hadfield são especificadas pela norma ASTM A128 [4]. Segundo a norma, os teores de C variam de 0,7 a 1,45\%, e os teores de $\mathrm{Mn}$ variam de 6 a14\% [4]. Os teores de $\mathrm{C}$ e a presença de elementos de liga tais como $\operatorname{Cr}(1,5$ a 2,5\%), Mo $(0,9$ a 1,2\%) e Ni (3 a $4 \%$ ) na composição química são os principais fatores que diferenciam os dez graus dos aços Hadfield, de acordo com a norma ASTM A128 [4]. Adicionalmente a esses graus da norma ASTM A128, as empresas produtoras de componentes de aço Hadfield têm desenvolvido novas classes, com teores mais elevados de $\mathrm{Mn}$.

A melhoria das propriedades mecânicas de resistência ao desgaste e tenacidade dos aços Hadfield é fundamental para elevar a vida útil dos componentes de engenharia. Existe a possibilidade de aperfeiçoar a vida útil destes componentes pela redução do tamanho de grão austenítico, que é o único meio de aumentar o limite de escoamento sem reduzir a tenacidade de ligas metálicas [8-10]. O uso do háfnio como refinador do grão austenítico é descrito em patente europeia [11], que descreve a adição de háfnio em quantidades de 0,01 a $0,1 \%$ em peso num aço Hadfield com 1,2\% C e 12,5\% Mn [11].

O objetivo deste trabalho é estudar o efeito da redução do tamanho de grão austenítico nas propriedades mecânicas de tração do aço Hadfield fundido e submetido ao tratamento térmico de solubilização.

\section{MATERIAIS E MÉTODOS}

As corridas experimentais foram realizadas em forno de indução na fundição piloto do IPT (Instituto de Pesquisas Tecnológicas), utilizando argônio para a proteção do banho metálico e adição de $\mathrm{Al}(0,1 \%)$ para a desoxidação. Foi realizada uma corrida experimental para cada uma das condições investigadas: aço Hadfield sem refino e refinado com adição de $0,1 \%$ de $\mathrm{Hf}$. A temperatura de vazamento dos corpos de prova de aço Hadfield foi mantida na faixa de 1430 a $1450^{\circ} \mathrm{C}$. Em cada 
corrida, foram fundidas peças do tipo "keel block" (120 mm de comprimento e $30 \mathrm{~mm}$ de espessura), usadas para retirada dos corpos de prova de tração, e blocos com dimensões de $60 \mathrm{~mm} \times 40 \mathrm{~mm} \times 80 \mathrm{~mm}$ para retirada dos corpos de prova para a caracterização macroestrutural. As análises químicas dos teores de $\mathrm{Si}, \mathrm{Mn}, \mathrm{P}$ e $\mathrm{Cr}$ no aço Hadfield foram realizadas pela técnica de espectroscopia de fluorescência de raios $X$ no equipamento Shimadzu XRF 1500. A determinação dos teores de $C$ e $S$ no aço foi realizada por combustão direta e detecção de IF no equipamento LECO CS 300. Todos estes ensaios fazem parte do Sistema de Qualidade do IPT. Os resultados da análise química estão descritos na tabela 1, e mostraram que todas as peças fundidas possuem composição química de acordo com a norma ASTM A128, grau B2.

Tabela 1. Composição química das amostras de aço Hadfield

\begin{tabular}{|c|c|c|c|c|c|c|c|}
\hline Amostras & $\% \mathbf{C}$ & $\% \mathbf{S i}$ & $\% \mathbf{M n}$ & $\% \mathbf{C r}$ & $\% \mathbf{P}$ & $\% \mathbf{S}$ & $\% \mathbf{N}$ \\
\hline Aço Hadfield semrefino & 1,23 & 0,64 & 11,98 & 0,0049 & 0,034 & 0,037 & 0,0178 \\
\hline Aço Hadfield refinado com Hf & 1,24 & 0,8 & 11,83 & 0,0035 & 0,034 & 0,037 & 0,0192 \\
\hline
\end{tabular}

Todas as peças foram submetidas ao tratamento térmico de solubilização de carbonetos a $1120^{\circ} \mathrm{C}$. O tempo de tratamento térmico foi de $4 \mathrm{~h}$ para as peças do tipo "keel block" e de 10h para as peças do tipo bloco. A solubilização foi seguida por resfriamento rápido em água agitada até a temperatura ambiente. As amostras metalográficas foram preparadas através das técnicas convencionais, utilizando ataque químico com Nital. A microestrutura foi observada na lupa e no microscópio eletrônico de varredura (MEV) Jeol JSM 6300. Adicionalmente, a técnica de difração de elétrons retro-espalhados (EBSD - electron back scattering diffraction) acoplada ao MEV foi usada para a caracterização microestrutural e cristalográfica dos grãos austeníticos.

O tamanho de grão da zona equiaxial do aço Hadfield sem refino e do aço Hadfield refinado foi medido como sendo a média entre a maior dimensão e a menor dimensão do grão austenítico. As medidas foram realizadas durante o exame macroestrutural das amostras atacadas quimicamente. Foram realizadas cinco medições para cada condição (aço Hadfield sem refino e refinado).

Finalmente, os ensaios de tração monotônica axial foram realizados no equipamento MTS Sintec, utilizando o extensômetro EX-001, o micrômetro MC-006 e o paquímetro PQ-008, todos eles calibrados pelo Centro de Metrologia Mecânica, Elétrica e de Fluidos (CTMNE) do IPT. As superfícies de fratura dos corpos de prova rompidos nos ensaios de tração foram caracterizadas no microscópio eletrônico de varredura (MEV) Jeol JSM 6300. As seções transversais destes corpos de prova também foram investigadas metalograficamente, usando microscopia óptica e eletrônica (imagem de elétrons secundários, imagem de elétrons retro-espalhados e EBSD). 


\section{RESULTADOS E DISCUSSÃO}

\subsection{Caracterização macro e microestrutural dos corpos de prova fundidos e tratados termicamente.}

A figura 1 mostra as macrografias dos corpos de prova do aço Hadfield nas condições sem refino (1-a) e refinado (1-b). Observa-se que o aço Hadfield na condição sem refino (figura 1-a) apresenta três zonas macroestruturais de solidificação: zona coquilhada, próxima a superfície; zona colunar e zona equiaxial na região central da peça. A zona coquilhada ocupa uma extensão muito pequena e não foi medida. A zona colunar possui $15 \mathrm{~mm}$ de extensão na direção da superfície para o centro da peça e a zona equiaxial possui aproximadamente $40 \mathrm{~mm}$ de extensão na região central da peça. O comprimento dos grãos colunares é de aproximadamente $4000 \mu \mathrm{m}$ e o tamanho dos grãos equiaxiais é de $3000 \mu \mathrm{m}$. O aço Hadfield refinado também apresenta uma pequena zona coquilhada, mas não se observa uma zona colunar nesse corpo de prova (figura 1-b).

As figuras 2-a e 2-b permitem comparar as macrografias da zona equiaxial do aço Hadfield da condição sem refino com a do aço Hadfield refinado com $\mathrm{Hf}$. Observa-se para a condição refinada (figuras 1-b e 2-b) que a macroestrutura do corpo de prova não possui uma zona colunar bem definida. Observa-se ainda uma distribuição uniforme de grãos equiaxiais, com tamanho aproximado de $600 \mu \mathrm{m}$.

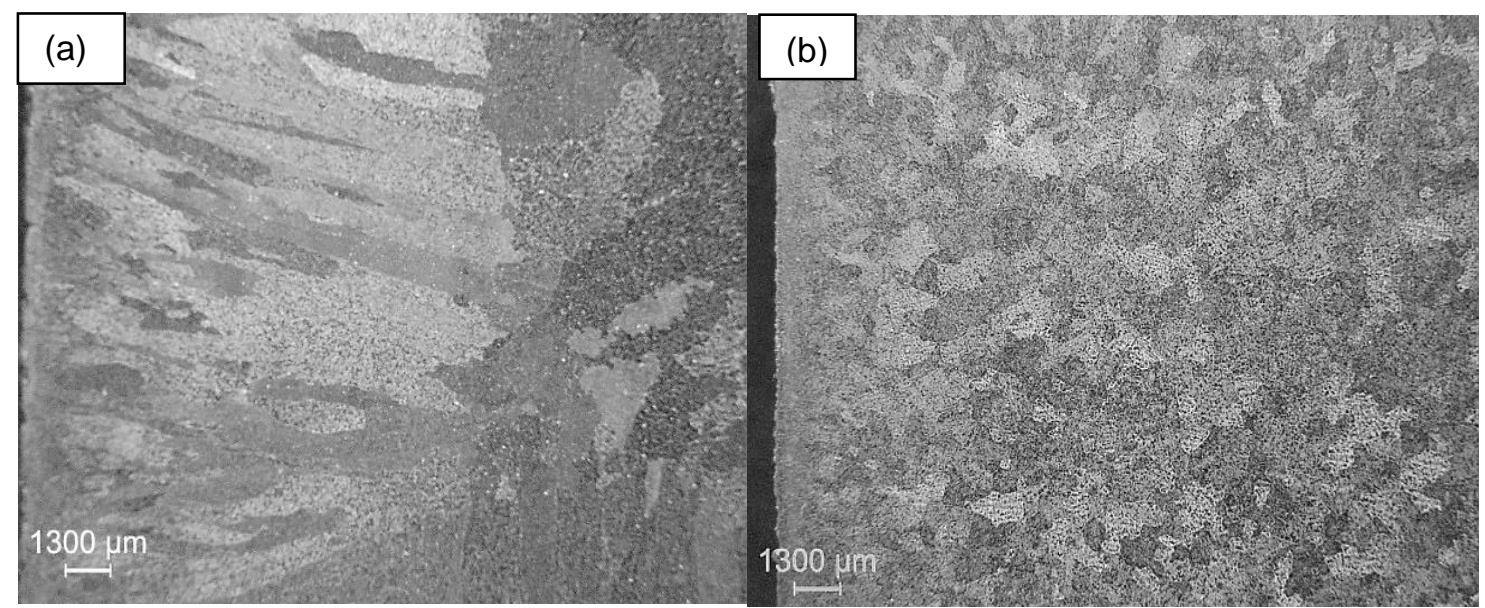

Figura 1. Macroestrutura da amostra fundida. Comparação entre (a) zona coquilhada e colunar do aço Hadfield sem refino e (b) região próxima à superfície do aço Hadfield refinado. Aumento original de 7,3x. Ataque químico: Nital 6\%. Exame em lupa. 


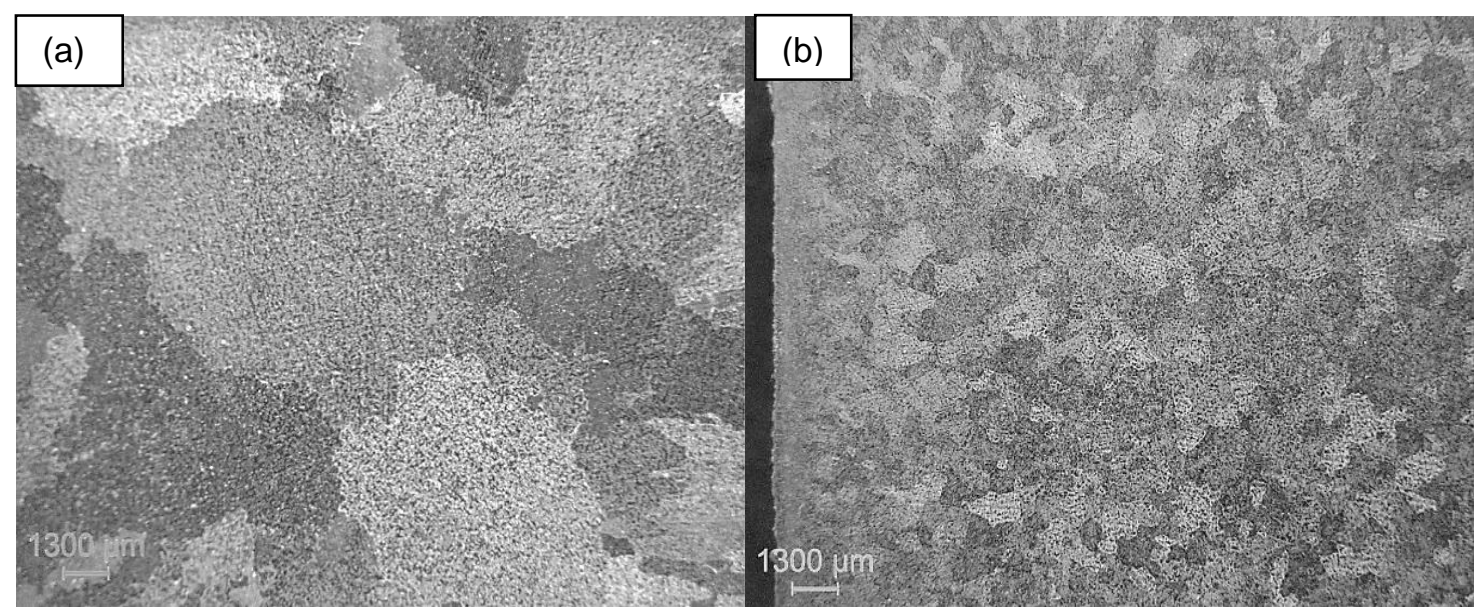

Figura 2. Macroestrutura da amostra fundida. Comparação entre (a) região equiaxial do aço Hadfield sem refino e (b) região central do aço Hadfield refinado. Aumento original de 7,3x. Ataque químico:

Nital 6\%. Exame em lupa.

A técnica de EBSD foi utilizada para confirmar o refino do tamanho de grão austenítico na amostra refinada. Os resultados são mostrados nas figuras 3 a 5 a seguir. Observa-se na figura 3 que os grãos da região colunar do aço Hadfield sem refino possuem orientação preferencial ao longo das direções $<100>$. Este resultado está de acordo com a literatura, que mostra que, para metais do sistema cúbico de face centrada (CFC), os grãos da região colunar posicionados com direção <100> perpendicular à parede do molde apresentam maior condutividade térmica e crescimento preferencial em relação aos grãos com outras orientações cristalográficas [12].
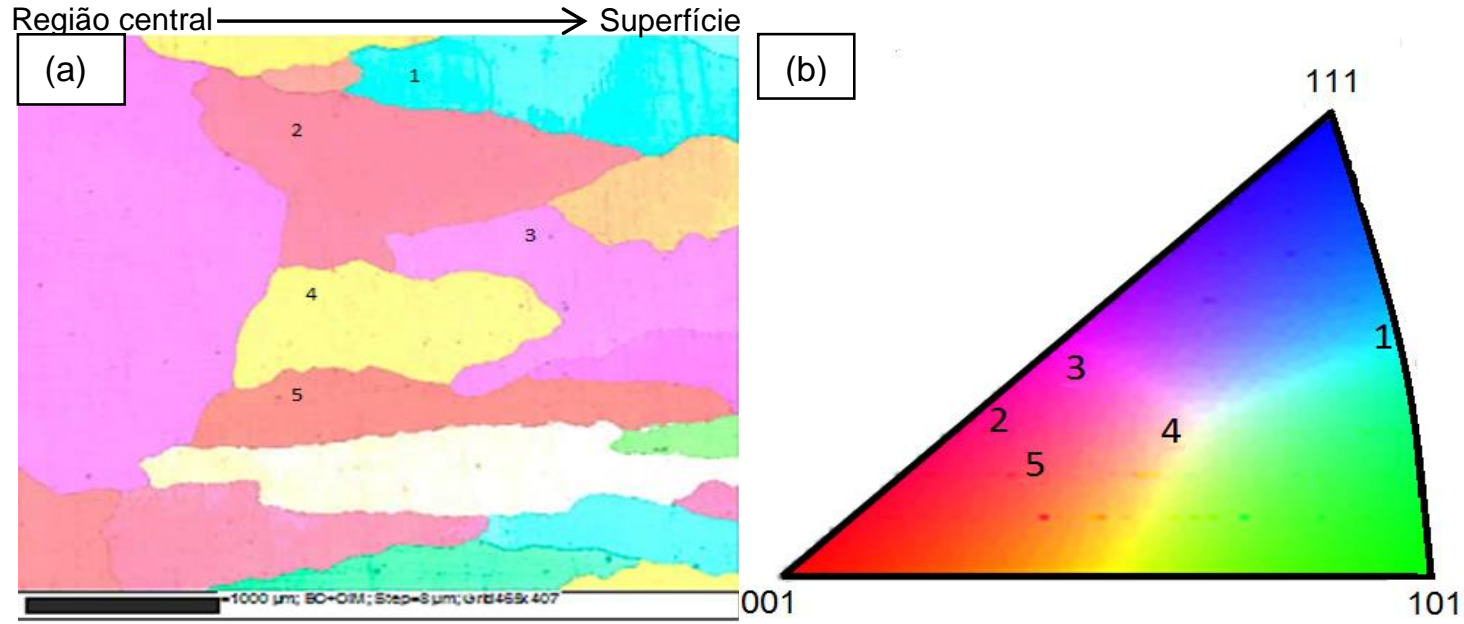

Figura 3. Aço Hadfield sem refino. (a) Resultado da técnica EBSD na região colunar do aço Hadfield. Ataque químico: Nital 3\%; (b) Indicação dos grãos marcados em (a) na figura de polo inversa para o sistema cúbico.

Adicionalmente, o exame dos grãos equiaxiais da região central do aço Hadfield sem refino (figura 4-a) indica a presença de uma pequena desorientação cristalográfica dentro de um grão de austenita, como mostrado na figura de polo 
inversa (figura 4-b), indicando a presença de contornos de sub-grãos (sub-grãos da ordem de $1500 \mu \mathrm{m})$.

No aço Hadfield refinado (figura 5-a), os grãos equiaxiais possuem orientação cristalográfica aleatória, como está indicado na figura de polo inversa para o sistema cúbico (figura 5-b). Os grãos austeníticos têm um tamanho de aproximadamente 600 $\mu \mathrm{m}$, não sendo observada a presença de sub-grãos.

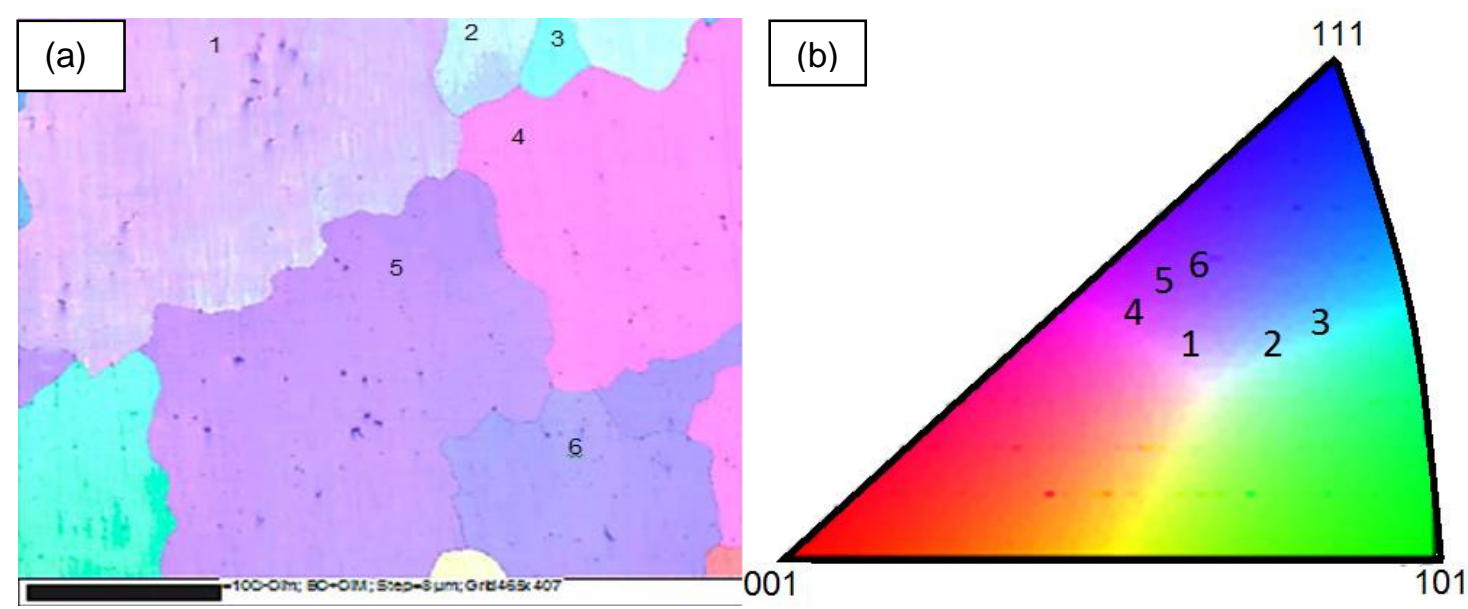

Figura 4. Microestrutura da amostra solubilizada, aço Hadfield sem refino. (a) Resultado da técnica EBSD na região central (grãos equiaxiais) do aço Hadfield sem refino. Ataque químico: Nital 3\%; (b) Indicação dos grãos marcados em (a) na figura de polo inversa para o sistema cúbico.
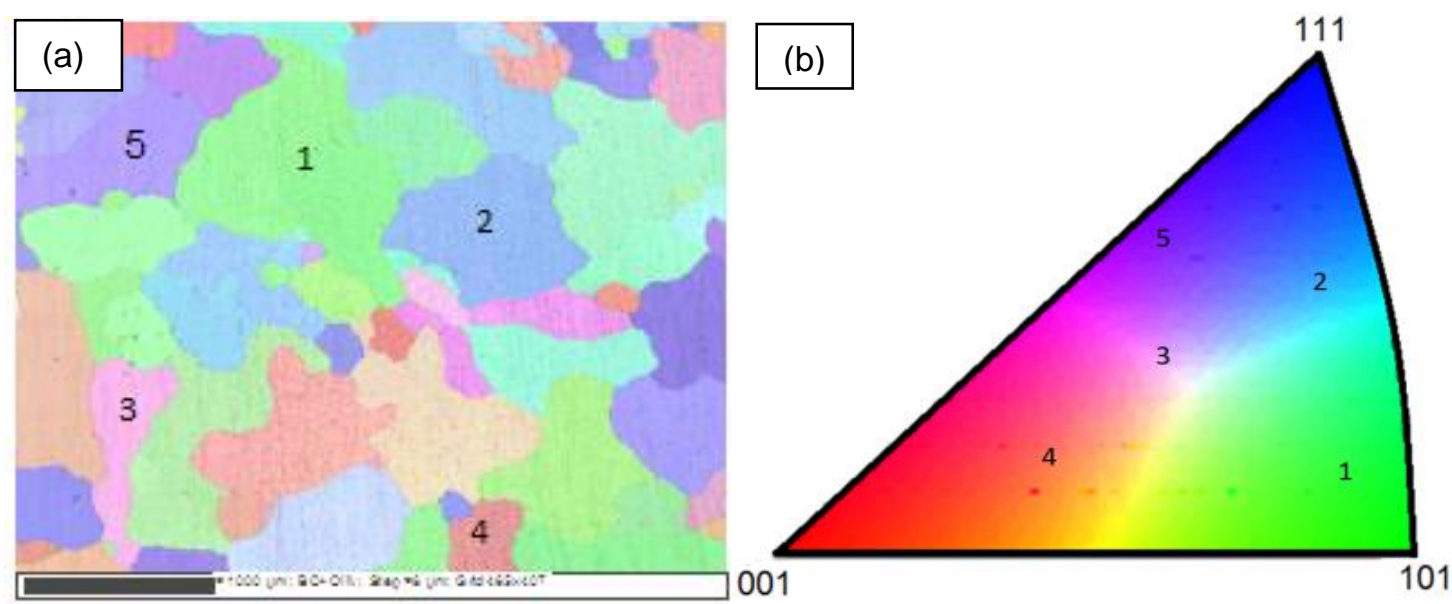

Figura5. Microestrutura da amostra solubilizada, aço Hadfield refinado com 0,1\% Hf. (a) Resultado da técnica EBSD na região central do aço Hadfield refinado com Hf. Ataque químico: Nital 3\%; (b) Indicação dos grãos marcados em (a) na figura de polo inversa para o sistema cúbico.

\subsection{Resultados do ensaio de tração das amostras solubilizadas}

A tabela 2 mostra a comparação dos valores médios das propriedades de tração entre o aço Hadfield sem refino e refinado. Os valores do limite de escoamento, limite de resistência e alongamento foram obtidos diretamente do ensaio de tração, e as propriedades de resiliência e tenacidade foram calculados a partir das curvas tensão x deformação do ensaio de tração. Observa-se na tabela 2 
um pequeno aumento do limite de escoamento (6\%) e resiliência ( $8 \%$ ) com a diminuição do tamanho de grão. No entanto, a resistência à tração do aço Hadfield refinado aumentou em 37\%, e seu alongamento aumentou em 53\% em comparação com 0 aço Hadfield sem refino (valores médios). Adicionalmente, os valores estimados da tenacidade, mostraram que o refino aumentou essa propriedade em aproximadamente $88 \%$.

Tabela 2. Comparação entre as propriedades de tração do aço Hadfield sem refino e do aço Hadfield refinado (valor médio de 3 ensaios).

\begin{tabular}{|c|c|c|c|}
\hline Propriedades & Sem refino & Refinado & Variação (\%) \\
\hline Limite de escoamento (MPa) & $334 \pm 3$ & $355 \pm 2$ & $\uparrow 6$ \\
\hline Resistência à tração (MPa) & $681 \pm 3$ & $931 \pm 4$ & $\uparrow 37$ \\
\hline Resiliência (J) & $282 \pm 4$ & $304 \pm 4$ & $\uparrow 8$ \\
\hline Tenacidade (J) & $409 \pm 3$ & $771 \pm 3$ & $\uparrow 88$ \\
\hline Alongamento (\%) & $47 \pm 1$ & $71 \pm 1$ & $\uparrow 53$ \\
\hline
\end{tabular}

O pequeno aumento do limite de escoamento $(6 \%)$ com a redução do tamanho de grão está em acordo com a equação de Hall-Petch (equação 1 abaixo) para cristais do tipo CFC, que possuem valores relativamente baixos para 0 coeficiente de Hall-Petch [8-10]. Por exemplo, a equação de Hall-Petch foi utilizada para extrapolar o aumento esperado no limite de escoamento utilizando os valores da constante de Hall-Petch ( $\mathrm{K}_{\mathrm{HP}}=0,452 \mathrm{MPa} \mathrm{m}^{1 / 2}$ ) e da tensão teórica para o limite de escoamento $\left(\sigma_{0}=318 \mathrm{MPa}\right)$ de um aço austenítico [13]. Os resultados sugerem um aumento de $12,5 \%$ no valor do limite de escoamento para um aço austenítico quando o tamanho de grão é refinado de $3000 \mu \mathrm{m}$ para $600 \mu \mathrm{m}$.

$$
\sigma_{e}=\sigma_{o}+K_{H P} \cdot d^{\frac{-1}{2}} \quad(\text { Equação 1) }
$$

Sendo: $\sigma_{e}=$ tensão de escoamento $(\mathrm{MPa}) ; \sigma_{o}=$ tensão teórica para o limite de escoamento de um monocristal (MPa); $K_{H P}=$ constante de Hall-Petch (MPa.m $\left.{ }^{1 / 2}\right) ; \mathrm{e}$ $\mathrm{d}=$ tamanho de grão $(\mathrm{m})$.

\subsection{Exame fractográfico}

As superfícies de fratura dos corpos de prova solubilizados e rompidos durante o ensaio de tração dos aços Hadfield sem refino e refinado são mostradas nas figuras 6 e 7. As fractografias do aço Hadfield sem refino (figuras 6-a e 6-b) apresentam alvéolos que são característicos da fratura dúctil. Observa-se a presença de dois tamanhos diferentes de alvéolos, um tipo mais grosseiro, com diâmetro aproximado de $10 \mu \mathrm{m}$, e outro mais refinado, com diâmetro aproximado de $2 \mu \mathrm{m}$. O exame fractográfico do aço Hadfield refinado (figuras 7 -a e 7-b) mostra uma fratura tipicamente intergranular com trincamentos secundários e possível presença de "poros". A figura 7-b mostra a presença de alvéolos ao longo dos contornos dos grãos austeníticos, indicando que a fratura ocorreu pelo mecanismo de fratura do tipo intergranular dúctil. 


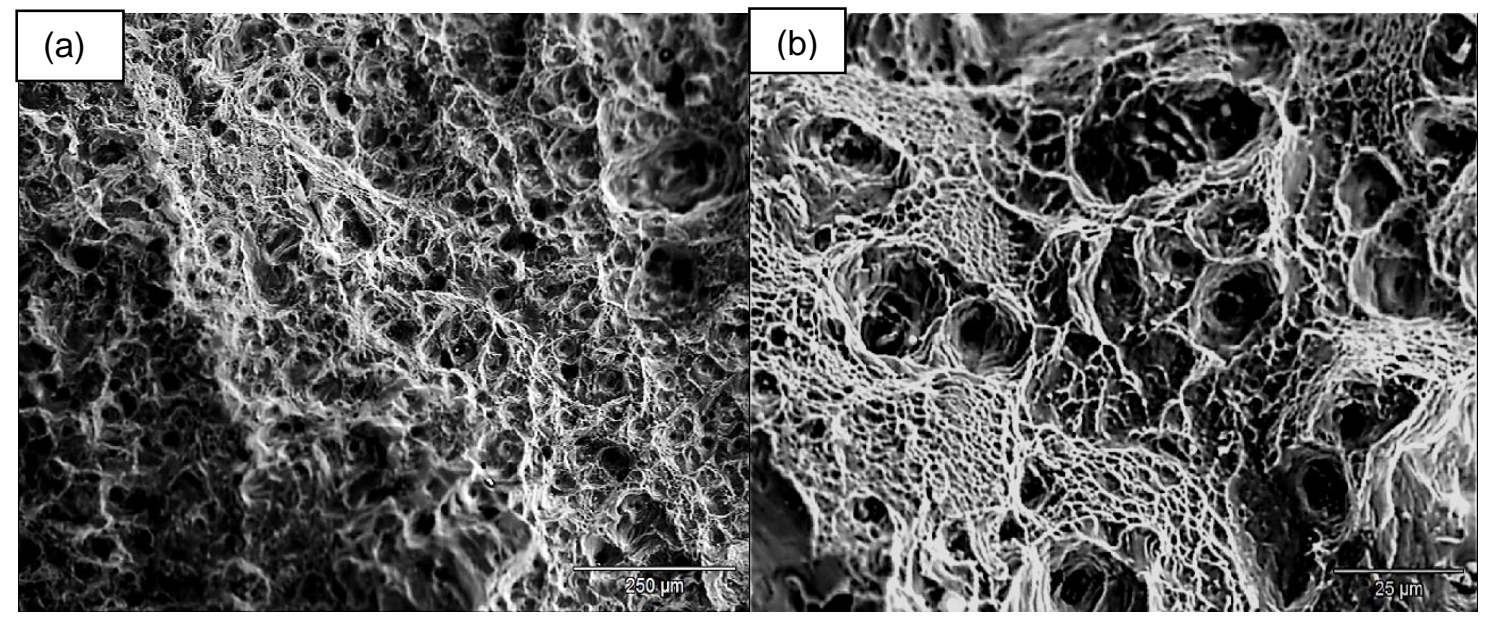

Figura 6. Exame fractográfico (MEV). Aço Hadfield sem refino, detalhe da região central mostrando dois tamanhos distintos de alvéolos, MEV, IES, 800x

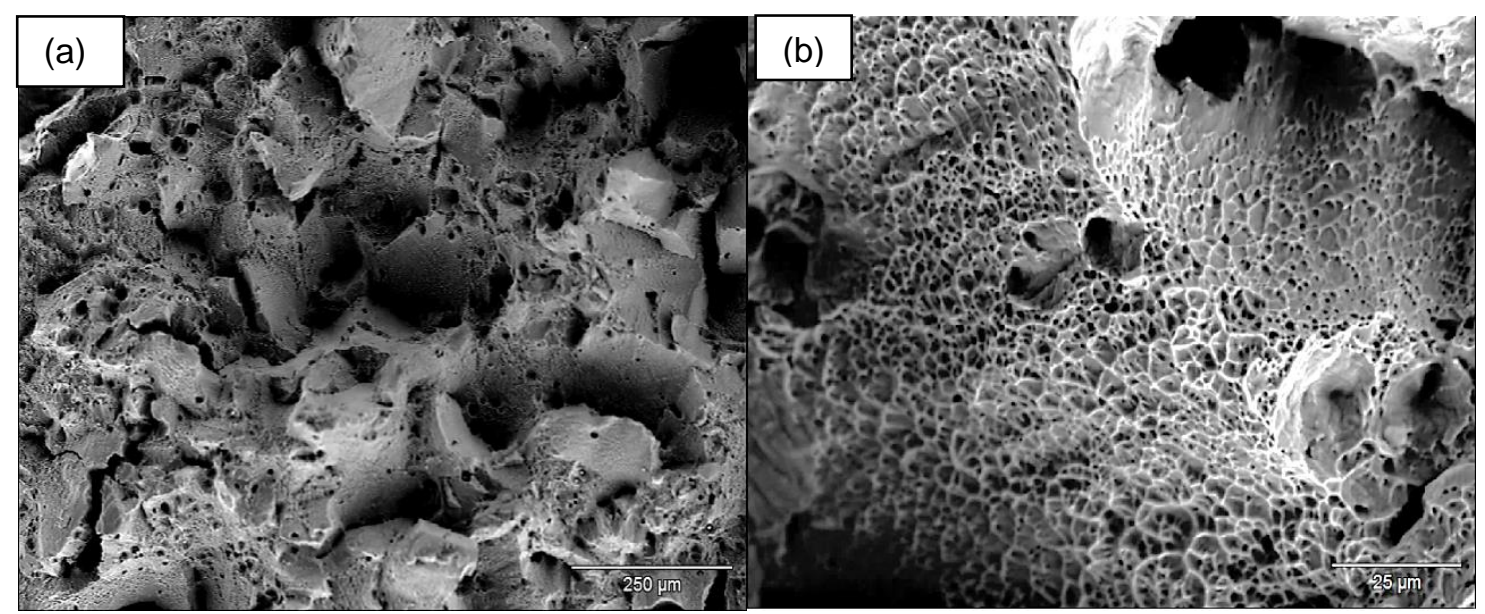

Figura 7. Exame fractográfico (MEV). (a) aço Hadfield refinado, detalhe da região central mostrando fratura intergranular, trincamento secundário e "poros", MEV, IES, 100x; b) detalhe dos alvéolos intergranulares, MEV, IES, 800x.

\subsection{Exame metalográfico das amostras fraturadas}

As figuras 8-a e 8-b mostram a microestrutura na seção transversal próxima à superfície de fratura, utilizando microscopia óptica. $\mathrm{O}$ aço Hadfield sem refino (figura 8-a) apresenta micro porosidades com comprimento de aproximadamente $50 \mu \mathrm{m}$ e inclusões com diâmetro de aproximadamente $1 \mu \mathrm{m}$, possivelmente relacionados com os dois tamanhos diferentes de alvéolos mostrados anteriormente no exame fractográfico (figura 6-b). Observa-se também uma trinca secundária com comprimento em torno de $720 \mu \mathrm{m}$. A caracterização microestrutural do aço Hadfield refinado mostra a presença de micro porosidades com diferentes comprimentos, na faixa de 10 a $40 \mu \mathrm{m}$, além de inclusões com diâmetro em torno de $1 \mu \mathrm{m}$.

As figuras 9-a e 9-b mostram a microestrutura na seção transversal próximo da superfície de fratura usando a técnica de EBSD. O corpo de prova do aço Hadfield sem refino (figura 9-a) possui maclas de deformação com comprimento em torno de $800 \mu \mathrm{m}$, enquanto que as maclas de deformação presentes no corpo de prova do aço Hadfield refinado (figura 9-b) possuem comprimento de aproximadamente $500 \mu \mathrm{m}$. A comparação entre as figuras 9-a e 9-b sugere que a 
deformação por maclação é mais intensa para a condição refinada, visto que a quantidade de maclas por mm é de 22 para o aço Hadfield sem refino e de 37 para o aço Hadfield refinado, correspondendo a um aumento de aproximadamente $60 \%$. Este fato contraria os resultados obtidos por Zhuetet al [14], que mostraram diminuição da fração de grãos maclados com a redução do tamanho de grão,na deformação plástica do Ni. Gadheriet al [15] observaram resultados semelhantes para o Ti.

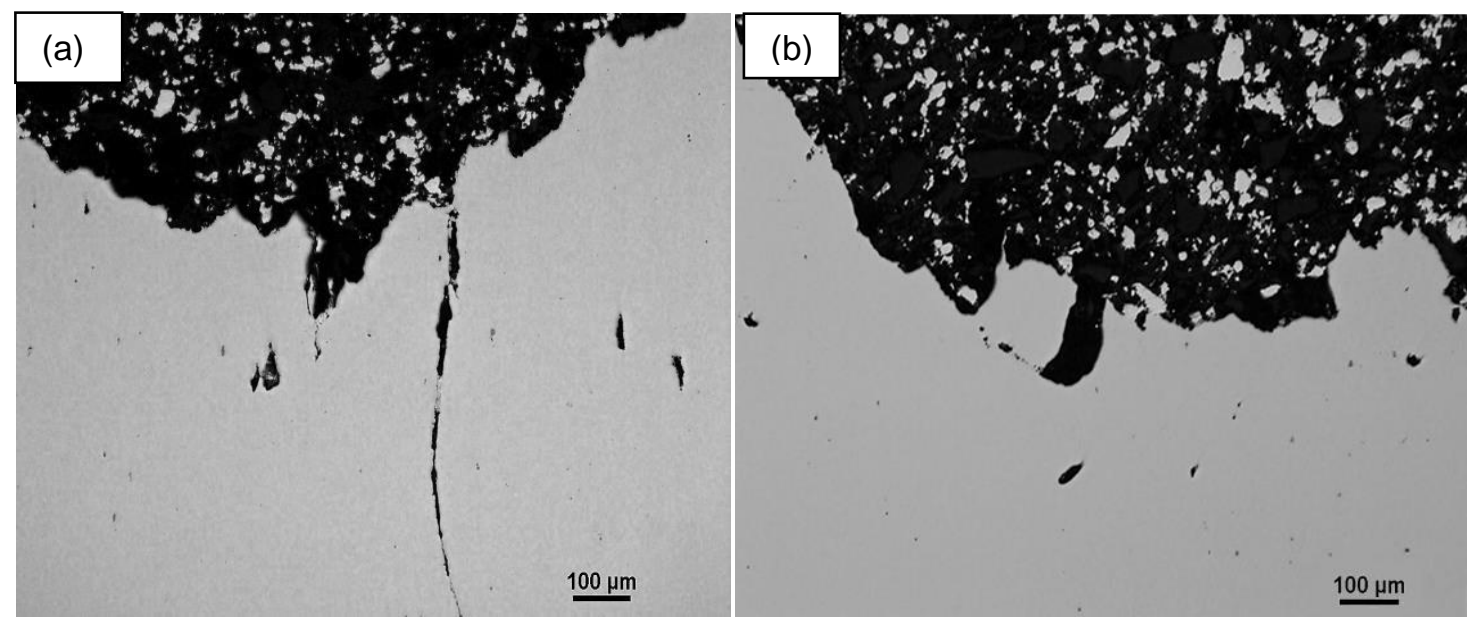

Figura 8. Exame microestrutural, corte transversal á superfície de fratura, sem ataque químico. Aumento de 100x. (a) aço Hadfield sem refino, mostrando inclusões, micro porosidades e um trincamento secundário; (b) aço Hadfield refinado, mostrando micro porosidades e inclusões.
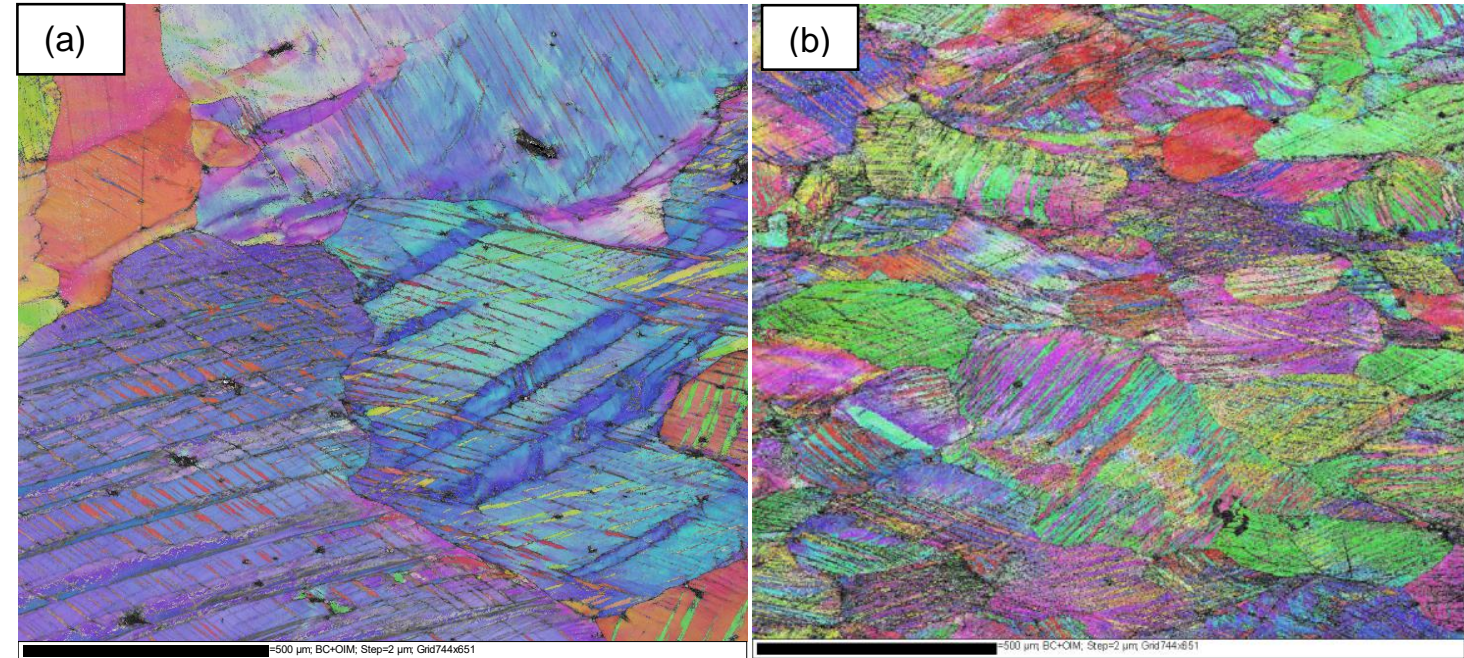

Figura 9. Microestrutura próxima da região da fratura das amostras tracionadas, seção transversal, técnica de EBSD. Região central (grãos equiaxiais) dos corpos de prova rompidos no ensaio de tração. a) aço Hadfield sem refino com presença de maclas de deformação plástica; b) aço Hadfield refinado com intensa presença de maclas de deformação plástica. 


\section{CONCLUSÃO}

- A caracterização macro e microestrutural mostrou que o aço Hadfield com adição de $\mathrm{Hf}$ apresenta tamanho do grão austenítico aproximadamente 5 vezes menor do que o tamanho de grão do aço Hadfield sem refino (de 3000 $\mu \mathrm{m}$ para $600 \mu \mathrm{m})$.

- O pequeno aumento obtido no limite de escoamento (6\%) com o refino de grão está compatível com as extrapolações obtidas usando a equação de Hall-Petch.

- O refino de grão austenítico causou aumentos significativos nos valores de resistência à tração (37\%), alongamento (53\%) e tenacidade (88\%).

- O refino do grão alterou o mecanismo de fratura de fratura dúctil para fratura intergranular dúctil.

- O refino do grão intensificou a ativação de deformação plástica por maclação.

\section{Agradecimentos}

À CAPES pela bolsa de estudos, 2015, n01564518. Ao programa Novos Talentos do Instituto de Pesquisas Tecnológicas (IPT) e à Fundação de apoio ao IPT (FIPT) pela disponibilização das instalações e apoio financeiro. $E$ a todos os integrantes do Centro de Tecnologia em Metalurgia e Materiais (CTMM) do IPT pelo apoio e execução dos ensaios experimentais.

\section{REFERÊNCIAS}

1. Hadfield, R.A. Hadfield's manganese steel. Science. 1888, 12, 284-286.

2. Tweedale, G. Sir Robert Abbott Hadfield F.R.S. (1858-1940) and the discovery of manganese steel.Notes \& Records of the Royal Society. 1985, 40, 63-74.

3. Giraldo, A. V. El acero Hadfield revisitado. Revista Colombiana de Materiales. 2012, 3, 1-24.

4. ASM Metals Handbook.Properties and Selection of Iron: Steels and High Performance Alloys, vol. 1, p. 1951-2003, 1993.

5. Dastur, Y. N; Leslie, W. C. Mechanism of Work Hardening in Hadfield Manganese Steel.Metallurgical Transactions A. 1981, 12A, 749-759.

6. Fuoco, R., Todorov, D; Cavalcanti, A. H.; Santos, N. L. Effect of chemical composition on the carbide reprecipitation kinetics of Hadfield austenitic manganese steel. Transactions of American Foundry Society. 2012, 120, 507522.

7. Santana, A. L. Manganês. Sumário Mineral, 2012. Disponível em: https://sistemas.dnpm.gov.br/publicacao/mostra_imagem.asp?IDBancoArquivoAr quivo=7528. Acessoem: 05/12/2016.

8. Hall, E. O. The deformation and ageing of mild steel: III - Discussion of results. Proceedings of the Physical Society. 1951, 64, 747-753.

9. Petch, N. J. The Cleavage Strength of Crystals.Journal of the Iron and Steel Institute. 1953, 174, 25-28.

10. Morris Jr., J. W. The influence of grain size on the mechanical properties of steel.Lawrence Berkeley National Laboratory.Disponívelem: http://escholarship.org/uc/item/88g8n6f8. Acessoem 02/05/2017. 
11. Oguiza, C. Hadfield steel with Hf. European Patent.10382335.7, 2012. 5p.

12. Krauss, G. Solidification, segregation and banding in carbon and alloy steels. Metallurgical and Materials Transaction B. 2003, 34, 781-792.

13. Kako, K; Kawakami, E; Ohta, J; Mayuzumi, M. Effect of various alloying elements on tensile properties of high purity Fe-18Cr-(14-16)Ni alloys at room temperature. Materials Transactions. 2002, 43 (2), 155-162.

14.Zhu, Y. T; Liao, X. Z.; Wu, X. L; Narayan, J. Grain size effect on deformation twinning and detwinning. Journal of Materials Science. 2013, 48, 4467-4475.

15. Ghaderi, A.; Barnett, M. R. Sensitivity of deformation twinning to grain size in titanium and magnesium.ActaMaterialia. 2011, 59, 7824-7839. 